\title{
Diffuse Cystic Bronchiectasis Associated with Left Microtia and External Auditory Canal Atresia: A Very Rare Coincidence
}

\author{
Mehmet Davutoglu $^{a}$ Cengiz Dilber ${ }^{a}$ Hasan Turut $^{b}$ Ekrem Guler ${ }^{a}$ \\ Hamza Karabiber ${ }^{a}$ Selma Guler ${ }^{c}$ \\ Departments of a Pediatrics and ${ }^{b}$ Thoracic Surgery, Faculty of Medicine, Sutcu Imam University, and \\ 'Department of Infectious Diseases, Yenisehir Hospital, Kahramanmaras, Turkey
}

\section{Key Words}

Bronchiectasis · Microtia · External auditory canal atresia

\begin{abstract}
Objective: To present a case in which diffuse cystic bronchiectasis was associated with left microtia/external auditory canal atresia. Clinical Presentation: A 10-year-old girl suffering from cough, fever, dyspnea and sputum for 6 months was transferred to our clinic due to the diagnosis of bronchopneumonia. She had recurrent episodes of bronchopneumonia. On examination, left microtia and left external auditory canal atresia were detected. Thorax $\mathrm{CT}$ revealed diffuse cystic bronchiectasis on the left lung. Radiological examination showed atresia of the left external auditory canal. We could not find any etiopathological reason causing bronchiectasis. Intervention: The patient underwent left pneumonectomy and postoperative histopathology was reported as bronchiectasis. Conclusion: This report shows a unique case in which an association of diffuse cystic bronchiectasis and left microtia/external auditory canal atresia was observed. Hence in newborns with microtia and/or external auditory canal atresia, the probability of development of bronchiectasis should be borne in mind and such patients should be followed up more carefully regarding this rare association.
\end{abstract}

Copyright @ 2008 S. Karger AG, Basel

\section{KARGER}

Fax +4161306 1234 E-Mail karger@karger.ch www.karger.com
(C) 2008 S. Karger AG, Basel

1011-7571/08/0172-0164\$24.50/0

Accessible online at:

www.karger.com/mpp

\section{Introduction}

Bronchiectasis is a morphological term used to describe abnormal irreversibly dilated and often thickwalled bronchi. The disease is characterized by a copious amount of productive cough with chronic ill health. Causes are various, but include cystic fibrosis, aspiration, postinfectious airway obstruction, immune abnormalities, immotile cilia, posttransplantation states, and congenital bronchial lesions [1]. Also a variety of syndromes are known to be associated with bronchiectasis [2].

Herein, we present a very rare association of diffuse cystic bronchiectasis and left microtia/external auditory canal atresia in a 10 -year-old girl. To our knowledge, this is the first report of such an association.

\section{Case Report}

A 10-year-old girl suffering from cough, fever, dyspnea and sputum for 6 months was referred for medical treatment due to the diagnosis of bronchopneumonia at a local hospital. In a follow-up, her chest X-ray revealed pleural effusion compatible with empyema so she was transferred to our clinic. She had recurrent episodes of bronchopneumonia. On examination, she was malnourished and below the 3 rd percentile for height and weight. She was dyspneic and tachypneic associated with intercostal and subcostal retractions and had widespread pleural frotman on the left, and crepitant rales on the right lung fields. Left microtia and ex-
Dr. Mehmet Davutoglu

Department of Pediatrics, Faculty of Medicine

Kahramanmaras Sutcu Imam University

TR-46050 Kahramanmaras (Turkey)

Tel. +90 344221 2337, Fax +90 344221 2371, E-Mail drmdavutoglu@hotmail.com 

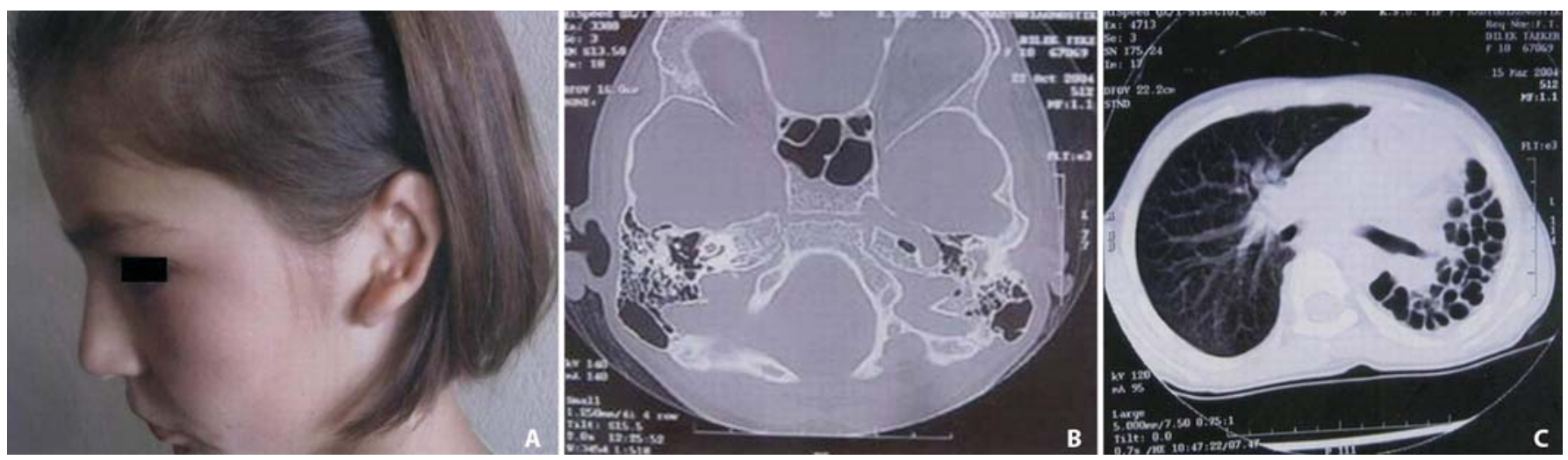

Fig. 1. A A photograph of the patient showing left microtia and external auditory canal atresia. B Cranial CT scan showing left external auditory canal atresia and left microtia. The middle and inner parts of the left ear have a normal anatomy. C Thorax CT scan showing diffuse cystic bronchiectasis of the whole left lung.

Table 1. Major defects associated with bronchiectasis

Cystic fibrosis
$\alpha_{1}$-Antitrypsin deficiency
Primary ciliary dyskinesia
Kartagener's syndrome (situs inversus, sinusitis and bronchiectasis)
Immunodeficiency states (e.g. hypogammaglobulinemia)
Young's syndrome (azoospermia and chronic sinopulmonary
infections)
Yellow nail syndrome (pleural effusions, lymphedema,
hypertrophic nails)
Connective tissue diseases (e.g. systemic lupus erythematosus,
rheumatoid arthritis)
Bronchomalacia
Williams-Campbell syndrome (bronchial cartilage deficiency)
Mounier-Kuhn syndrome (tracheobronchomegaly)
Swyer-James syndrome (unilateral hyperlucent lung)
Bronchopulmonary sequestration
Middle lobe syndrome

ternal auditory canal atresia were also detected (fig. 1A). Chest radiography revealed infiltrative areas on the right lung and diffuse opacity on the left. Cranial CT revealed atresia of the left external auditory canal (fig. 1B). The sweat chloride test for cystic fibrosis, purified protein derivative and HIV serology were negative. Immunoglobulin levels including immunoglobulin $G$ subclasses, total lymphocyte counts, and complement activity were all within normal limits and the nasal saccharin test was normal. The response to the Candida albicans antigen skin test was positive. No defect related with cellular and humoral immunity was found. Thorax CT showed diffuse cystic bronchiectasis of the whole left lung (fig. 1C). The patient underwent left pneumonectomy without any surgical complication. Postoperative histopathology was reported as bronchiectasis. She was doing well in the 32nd month of follow-up.

Bronchiectasis and Microtia

\section{Discussion}

Bronchiectasis is a pathologic description of lung damage characterized by inflamed and dilated thick-walled bronchi leading to chronic ill health, cough and a copious amount of sputum. It remains a challenge to the pediatric chest physicians in many developing parts of the world and is a frequent problem being the final common pathway of several different lower respiratory tract insults such as cystic fibrosis, immunodeficiency and ciliary dyskinesia [3]. In children, the common causes of bronchiectasis are tuberculosis, cystic fibrosis, retained foreign bodies, congenital anomalies like cystic adenomatoid malformations, immunodeficiency states, immotile cilia syndrome and bronchopulmonary sequestrations [4-6]. However, in noncystic fibrosis, infection was reported to be the most common cause followed by asthma, primary ciliary dyskinesia, congenital immune deficiency, and foreign body aspiration. It has also been observed that bronchiectasis is mostly located in the left lower lobes of the lung [7]. Whatever the underlying pathology may be, a chronic inflammatory condition progressively destroys the bronchial cartilage leading to permanent dilatation of the bronchial apparatus. Superadded infections in the diseased segments of the bronchi encourage bacterial overgrowth of opportunistic organisms and suppuration.

In our case, the sweat chloride test and purified protein derivative were negative and $\alpha_{1}$-antitrypsin deficiency was not present. Therefore, cystic fibrosis, tuberculosis and $\alpha_{1}$-antitrypsin deficiency were excluded in the differential diagnosis. There was no foreign body in the

Med Princ Pract 2008;17:164-166 
bronchi. Immotile cilia syndrome was excluded due to the normal histopathological and ultrastructural changes as well as evidence of unilateral involvement and negativity of the nasal saccharin test. No relation with primary ciliary dyskinesia was found. Since the etiology of our case was not related to the known etiological factors and evidence of left microtia/external auditory canal atresia was observed, we considered this condition as a very rare coincidence.

The most frequently found reason causing bronchiectasis was ciliary abnormality $[8,9]$. Major defects associated with bronchiectasis are shown in table 1 with ciliary abnormality as a causative factor $[8,9]$. Although Barbieri et al. [2] have reported that bronchiectasis was probably related to a grossly abnormal bronchial structure and atrophic-appearing bronchial mucosa as well as to hypo- gammaglobulinemia with functional antibody deficiency, no such gross abnormality in the bronchial system was present in our patient. Moreover, humoral and cellular immune defense findings were normal in our patient.

\section{Conclusion}

This report illustrates a very rare case in which an association of diffuse cystic bronchiectasis and left microtia/external auditory canal atresia was observed. Hence in newborns with microtia and/or external auditory canal atresia, the probability of developing bronchiectasis should be borne in mind and such patients should be followed up more carefully regarding this rare association.

\section{References}

1 Coleman LT, Kramer SS, Markowitz RI, Kravitz RM: Bronchiectasis in children. J Thorac Imaging 1995;10:268-279.

$\checkmark 2$ Barbieri EA, Bawle EB, Toder DS, Abdulhamid I, Bloom DA, Rabah-Hamad R, Secord EA: A syndrome of hypoplastic sinuses, hydrocephalus, bronchiectasis, and hypogammaglobulinemia. Ann Allergy Asthma Immunol 2005;94:693-699.

-3 Callahan CW, Redding GJ: Bronchiectasis in children: orphan disease or persistent problem? Pediatr Pulmonol 2002;33:492-496.
Tsao PC, Lin CY: Clinical spectrum of bronchiectasis in children. Acta Paediatr Taiwan 2002;43:271-275.

5 Edwards E, Asher M, Byrnes C: Paediatric bronchiectasis in the twenty-first century: experience of a tertiary children's hospital in New Zealand. J Paediatr Child Health 2003; 39:111-117.

6 Kolbe J, Wells AU: Bronchiectasis: a neglected cause of respiratory morbidity and mortality. Respirology 1996;1:221-225.
Dogru D, Nik-Ain A, Kiper N, Gocmen A, Ozcelik U, Yalcin E, Aslan AT: Bronchiectasis: the consequence of late diagnosis in chronic respiratory symptoms. J Trop Pediatr 2005;51:362-365.

8 Krawczynski MR, Dmenska H, Witt M: Apparent X-linked primary ciliary dyskinesia associated with retinitis pigmentosa and a hearing loss. J Appl Genet 2004;45:107-110.

$\checkmark 9$ Van's Gravesande KS, Omran H: Primary ciliary dyskinesia: clinical presentation, diagnosis and genetics. Ann Med 2005;37:439449. 